\title{
How IRBs View and Make Decisions About Consent Forms
}

\author{
Robert L. Klitzman \\ Columbia University
}

\begin{abstract}
IRBs have been criticized for long and complicated consent forms, but how IRBs make decisions about these issues hasn't been examined. I contacted leaders of 60 IRBs, and interviewed IRB leaders from 34 (response rate $=55 \%$ ), and 13 members and administrators. IRBs confront challenges and dilemmas regarding these documents: what and how much these forms should include (e.g., how "perfect" forms should be). While IRBs generally seek to decrease the length and complexity, institutions and industry funders often want these forms to be legal documents. IRBs may also "nitpick" these documents without realizing the costs. This study, the first to explore how IRBs view and make decisions about consent forms, suggests underlying tensions, ambiguities, and subjectivities that have important implications for future policy, practice, education, and research.
\end{abstract}

\section{Keywords}

research ethics committees; conflicts of interest (COIs); therapeutic misconception; comprehension; misunderstanding; research integrity; decision making

IRBs have been criticizedfor approving overly long and complicated informed consent forms and spending too much time on these documents' details, but the reasons involved remain unclear. IRBs are mandated to review and approve consent forms (U.S. Department of Health and Human Services, 2005), yet vary in the kinds and type and numbers of alterations they request (Stark, Tyson, \& Hibberd, 2009), which can increase refusal rates by potential participants (Dziak et al., 2005). Informed consent is important both in bioethics, to enhance beneficence and autonomy, and relatedly, in the law, where it can be critical in judging claims concerning liability and negligence (Faden \& Beauchamp, 1986).

Yet over time, forms have lengthened (Albala, Doyle, \& Appelbaum, 2010). Despite increased attention to informed consent, participants often understand these forms poorly (Krosin et al., 2006). Most university websites specify a modal reading level of eighth grade, but only $8 \%$ of these institutions meet their own standard (Paasche-Orlow, Taylor, \& Brancati, 2003). Moreover, participants may rely on trust in institutions and seek community benefit, more than detailed scientific accounts of research, which subjects tend not to remember (Dixon-Woods et al., 2007). Among researchers who had conducted studies in the developing world, 52\% thought that "legalistic language... was not meaningful" to participants (Dawson \& Kass, 2005). Such increased length and complexity can undermine comprehension, and thus the principles of informed consent itself. Interventions (e.g., simplified forms and multimedia formats) have had only limited and inconsistent success- 
though use of trained consent educators familiar with the study may show the most promise (Cohn \& Larson, 2007; Flory \& Emanuel, 2004).

Participants may understand and interpret informed consent differently than do IRBs and researchers. While participants may simply seek to trust the institution and "promote the common good," IRBs and researchers may continue to focus on "deficits" in participants' comprehension (a "deficit model") (Harper, 2007; Dixon-Woods, 2007; Molyneux, Peshu, \& Marsh, 2005). However, providing many scientific details about a study may be "mere disclosure," and not improve informed consent (O'Neill, 2004). Hence, such "comprehension deficits" may be inevitable (Dixon-Woods, 2007).

In July 2011, in response to criticisms of the status quo, the U.S. Office of Management and Budget released an Advance Notice of Proposed Rulemaking (ANPRM) to revamp IRB regulations. The ANPRM seeks to increase use of brief summary sheets and standardized templates (U.S. Department of Health and Human Services, 2011). This document proposes

limiting the acceptable length of various sections of a consent form...prescribing how information should be presented...such as information that should be included at the very beginning of the consent form... reducing institutional 'boilerplate' in consent forms (that is, standard language that does little to genuinely inform subjects, and often is intended to primarily protect institutions from lawsuits); and...making available standardized consent form templates, which could satisfy applicable regulatory provisions (ibid.).

Yet the ANPRM also poses several questions: "What factors contribute to the excessive length and complexity of informed consent forms, and how might they be addressed?" "Would the contemplated modifications improve the quality of consent forms? If not, what changes would do so?" (ibid.) Whether the ANPRM's recommendations become enacted, and if so, which, when, and how remains unclear.

Other, logistical aspects of IRBs have been examined-e.g., variations in time to approve protocols (Greene \& Geiger, 2006), decisions about risk (Shah et al., 2004), and member demographics (Bell, Whiton, \& Connelly, 1998; Campbell et al., 2003; De Vries \& Forsberg, 2002). IRB members may follow local precedents, and draw on professional as well as personal experiences; and discussions may be guided by the fact that memos will be produced as a result (Stark, 2012). But how IRBs themselves view and make decisions about consent forms has not been examined.

Recently, I interviewed IRB chairs, administrators, and members about a series of issues, focusing on research integrity (RI), broadly defined. I explored how IRBs made decisions about RI (Klitzman, 2011a), which proved related to their views and approaches concerning several areas, including conflicts of interest (COIs) (Klitzman, 2011b), PIs (Klitzman, 2011c), so-called "community" members (Klitzman, 2012a), central IRBs (Klitzman, 2011d), variations among IRBs (Klitzman, 2011e), and developing world research (Klitzman, 2012b). Participants also frequently discussed issues concerning informed consent. Since the study used qualitative methods, it permitted in-depth exploration of these issues. The present paper thus examines these data regarding participants' experiences, perspectives, and decisions regarding consent forms.

\section{Methods}

Briefly, as described elsewhere (Klitzman, 2011a-g), I conducted in-depth telephone interviews of two hours each with 46 chairs, directors, administrators, and members. I contacted the leadership of 60 IRBs (every fourth one in the list of the top 240 institutions 
by NIH funding), and interviewed IRB leaders from 34 of these institutions (response rate $=$ $55 \%$ ). In certain cases, both a chair/director as well as an administrator from an institution was included (e.g., if the former thought that the latter could better provide detail about certain areas). In all, as summarized in Table 1, I interviewed 39 chairs/directors and administrators from these 34 institutions. I also asked every other respondent interviewed on the list by amount of NIH funding to disseminate information about the study to their IRB members, to recruit one member from each IRB, and thus included seven other members, too.

The interviews focused on participants' views of RI, IRB responses, and factors involved, and also illuminated many other, broader issues including views and decisions about consent forms. The methods were informed by grounded theory (Strauss \& Corbin, 1990). I drew on participants' own words and perspectives to obtain a "thick description" (Geertz, 1973). (Additional methodological details are available online as supplemental material at dx.doi.org/10.1525/ jer.2013.8.1.8.)

\section{Results}

In brief, as outlined in Table 2 and elaborated below, IRBs face challenges interpreting ambiguous regulations concerning consent forms, and to do so in the context of social and institutional relationships with institutions, industry funders, and PIs. IRBs confront questions concerning both the form and content of consent forms (e.g., what to include, and how, and how to decide). Regulations contain uncertainties-e.g., how informed do subjects need to be. While IRBs generally seek to decrease length and complexity of these documents, institutions and industry funders often want these forms to be legal documents, increasing length and generating tensions. These forms themselves also have several inherent limitations.

\section{IRBs' Concerns about Subjects and PIs: Efforts to Protect Subjects}

IRBs feel they play a vital role in reviewing, and frequently rewording, consent forms in order to protect subjects, but many questions and challenges arise in doing so. IRBs feel many PIs submit overly long and complicated forms - and that PIs may underemphasize the risks and overemphasize the potential benefits of research. Yet IRBs often debate what exactly to change.

Given potential PI desires to downplay risks, revising these documents can be important to decrease researchers' "bias":

The informed consent should say, "This study will be of no benefit to you. It is designed to determine the drug's toxicity levels." But our cancer researchers refuse to go along with that. They want to say, "This study may or may not benefit you." (IRB38)

Subtle distinctions can become important. PIs may write that an experimental drug "is not yet approved by the FDA," not that it "was never approved"; or that a drug "has already been given to 15 people, and was generally well tolerated," rather than, it "has only been given to 15 people, and no one died."

IRBs may wrestle to strike a balance, wanting to neither eliminate hope nor oversell a treatment; but doing so can be hard, and IRBs may thus require additional detail to try to both enforce this distinction and achieve balance.

I want the forms to say: "These drugs are new and have never been tried in humans. In animals, they have been shown to have effects on problems similar to yours. 
There may be some applicability for humans." That's honest, as opposed to saying, "This may benefit you," or, “This isn't going to benefit you." It's telling the patient it's not going to help them, but it's not dashing their hope. (IRB38)

IRBs also struggle to take into consideration subjects' vulnerability. Patients may be stressed because of illness. In ERs, or when just diagnosed with life-threatening diseases, patients may simply not be able to concentrate on lengthy documents. Instead, such patients should ideally take forms home before signing them, or be given a "one-pager." Still, researchers or IRBs may feel that doing so is not feasible.

Patients in ERs, or diagnosed with cancer or HIV, are being asked, "Read this 25page form. If you're having chest pains, please review this protocol and tell me if you want to be in it." For cancer, they should say, "Take it home and come back next week, and let's talk about it." In the ER, it should be one page...They can't do the eight pages, and you don't want them to. (IRB3)

IRBs often blamed researchers and industry funders, not themselves, for problems with consents, seeing themselves as protecting subjects from PIs.

Patients may also have therapeutic misconceptions that IRBs seek to counter through these documents. Yet reversing potential therapeutic misconception may lengthen and complicate these documents.

Patients don't hear the specifics-the message, "This is research"-because they want to believe there's hope. The participant should join the study, being given the information correctly, and the chance to make an autonomous decision. (IRB16)

Given many potential subjects' wariness toward participating in research, researchers may be inherently conflicted as well, wanting to recruit subjects.

IRBs may see these forms as increasingly important since researchers may not know patients well, as in earlier eras. In the past, clinicians, who had known patients for many years, may have been more involved in studies. Consequently, the length of these documents and the potential importance of IRBs' roles in reviewing these may now be higher.

When more studies were investigator-initiated, the subjects were patients of the doctor doing the research. The docs were taking care of the patients, and had a relationship: so, let 'em do research. (IRB3)

In the absence of such ongoing relationships and trust, written consent may become more critical to establish the terms of interactions.

\section{Pressures to See Forms as Legal Contracts}

Despite these goals of protecting subjects, interviewees face a series of challenges due to ambiguities in the regulations, limitations in these documents, and pressures and competing priorities from outside stakeholders.

These strains partly reflect underlying tensions over whether consent forms are legal contracts versus informational documents for subjects-i.e., whether forms should protect participants or the institution. Interviewees often felt that pharmaceutical companies and institutions wanted these forms to be legal contracts.

There are longer consents, designed to indemnify the companies or universities, not protect subjects, or help subjects decide the risks or benefits of the study. (IRB4)

The lack of prior relationships and trust between researchers and subjects increases not only the potential importance of IRB reviews of these forms, but potentially the legal aspects of 
these documents. The companies, wanting to indemnify themselves, may make a push for such contracts, even if these are unclear or inapplicable in particular contexts. Complications may then arise, however, since subjects may not follow what they have signed to agree to do:

Consent forms tend to be very legalistic and proscriptive, "You must do this and that." Or, "I will not do this. I will use double contraception." Participants don't do that anyway, so they can say what they want. But companies require 55-year-old subjects to have pregnancy tests before studies! It's just there to protect the company, not help the participant decide whether they want to be in the study. (IRB3)

IRBs may feel unable to argue otherwise, and may try to negotiate, but vary in their ability to do so. ("The IRB says, 'This is ridiculous: a 22-page consent form.' ...But the company requires it. So, we try to compromise." [IRB25])

Industry funders, in writing forms to protect themselves rather than subjects or institutions, can range in cooperation and flexibility. ("Some have their absolutely rigid bottom line: 'This is what you're going to do."' [IRB25])

IRBs may feel limited in their abilities to counter such phenomena, and alter such documents.

In a couple of instances, we said, "We can't do this. It's just not right!" Generally, at that point, companies have been responsive if they want the study done. Usually, they get similar complaints from other institutions. (IRB25)

Corporations may thus alter forms only if several IRBs complain, highlighting the roles of wider social dynamics and contexts in these decisions.

These negotiations with a company may be easiest when they occur between two lawyers, underscoring the de facto legal aspects and functions of these documents.

Our contracts office knows how to work with the company and the company lawyers. Lawyer-to-lawyer is much different than PI-to-lawyer. A lot more gets accomplished. (IRB25)

To certain degrees, these documents may be both legal and ethical documents. But ambiguous boundaries and balance between these two models and sets of expectations can cause problems.

Academic institutions may also want these forms to be legal documents, and pressure IRBs to include language that explicitly reflects legal, not ethical, considerations. Lawyers may write templates that IRBs feel obligated to incorporate, including unnecessary verbiage that may not apply in particular situations.

Our university's boilerplate has a lot of wasted language that I'd like to take out, but the attorneys won't let me. The form says, "Before you sign this, you can take it to discuss with whomever you like." But, that doesn't make sense when a patient is about to have an urgent procedure. However, we aren't allowed to take it out! (IRB7)

These debates reflect, too, larger underlying tensions of whether IRBs should protect subjects versus others. Institutions may focus more on the former, while IRBs may focus on the latter. Within institutions, IRBs can ultimately feel overruled, directly or indirectly. Protecting the institution can conflict with protecting the subject. 
We had a Compliance Officer and an attorney talk about protecting the university. As chair, at times I'd say, "Yes, but that's a different consideration-not ours. That's for you to act on." But, at other times, unless certain changes were made, the study wasn't going forward: what would be the point of IRB approval if the Compliance Officer was going to reject it? (IRB7)

Given input from lawyers in an institution, IRBs may thus succumb to implicit or explicit pressure to treat these forms as legal documents. While IRBs may prefer to see these forms as primarily ethical, funders and academic institutions may see these documents as far more legal.

Interviewees may recognize this tension, and strive to err on the side of protecting the subjects (not the institution), but with only limited success.

We don't like consent forms with a lot of potentially exculpatory languageresearchers trying to protect the institution, and confuse participants. We'd rather err in the direction of protecting the participants, and maybe risking some institutional exposure...Usually these concerns come up when we're cooperating with another IRB. First, we object. Then they say, "I'm sorry, our lawyers will not let us change this." So we say, "OK, you can have it in there if you also agree to include a Q\&A sheet in layperson's terms." (IRB33)

Yet in multi-site studies, consent forms may then differ between institutions.

Interviewees felt at times that the inflexibility of boilerplate language due to lawyers or other bureaucratic input can become "absurd." One IRB reviewed a 35-page consent form for sight-impaired subjects.

We talked to the researchers about maybe tape recording it. They wanted to just do a CD that the patients would listen to in the office. I said no: patients are probably going to have to listen to this many times at home to try to figure it out. (IRB17)

Facing with conflicting pressures, IRBs may be able to arrive at alternative solutions or compromises.

Consent forms can also potentially impede psychosocial research. In qualitative research, investigators frequently seek to generate hypotheses, and cannot fully describe beforehand all research questions and scenarios. For a PI to anticipate and include in the consent all that he/she will ask may be hard, if not impossible.

Just describing in advance all the settings in which he might interview people, and their social roles - if he then had to adhere to that, and never go beyond that - it would restrict what he does. Yet if he were to describe it all in advance, I'm not sure an IRB would find it as acceptable. (IRB7)

IRBs may also lack sufficient expertise to review psychosocial research adequately, and thus to appreciate these challenges. Still, though documents can potentially do harm, some form of consent may be needed.

But at times even this interviewee felt he had to accept these forms' status as legal documents. He realized subjects may not fully comprehend these statements, but he felt that he had little, if any, alternative.

The consent form is a legal document-a contract. There has to be full disclosure of everything that could pose a risk. That makes it very long. Whether people read it thoroughly varies. They could streamline the language a lot. (IRB7) 
He still felt frustrated, not always able to shorten forms. He and others also blame funders and PIs, not IRBs, for excessive length.

Many IRBs may try not to succumb too much to institutional lawyers' input, but that goal can be difficult.

We try really hard not to cave in to our legal or contracts department. They try to get us to standardize consents. It may take us longer to review studies because we don't give researchers a cookie cutter form. Our approach is not necessarily efficient. (IRB33)

Tradeoffs thus arise between using templates versus taking more time to review each form.

Based partly on training of their individual memberships, IRBs vary in how much they feel they have to follow versus how much they can oppose their institutions' lawyers. The chair above was able to fight institutional lawyers, partly because this IRB included a skilled attorney.

We have an outside lawyer on our IRB who's really good. I would put him up against any in-house lawyer. If the institution's lawyer said, "You have to use exactly this language," our whole IRB would resign. (IRB33)

Yet other IRBs may feel less able to resist such pressure.

\section{Dilemmas about Consent: What and How Much to Include}

IRBs face further tensions about how complete and long these forms should be, and how much to edit. More detail and explanation can lengthen and complicate forms. IRBs often struggle since regulations are unclear as to how detailed or informative these documents should be, leaving these decisions up to these committees, which can then differ. IRBs wrestle with these tensions between completeness versus comprehension, seeing a "fine line" (IRB29). Tradeoffs exist between informing subjects of all versus only the most important risks. Some interviewees complained of efforts to inform subjects of as much as possible. Few, if any, checks countered increases in length that IRBs sanctioned or encouraged.

Sometimes the list of risks is almost ridiculous-it goes on and on and on. The list of risks for one drug is three pages long. Can't we simplify it? The patient probably just ignores all of it. Would it be possible to talk more about the likely risks, rather than a two-page list? Patients just say, "I can't be bothered with that. I'll sign it." (IRB37)

Still, these concerns did not always prompt shorter forms. Other IRBs may indeed encourage completeness, seeing it as beneficial. ("Researchers may think our IRB is a little more overthe-top than the regulations require. We require our researchers to be a lot more thorough." [IRB35]) Yet such completeness may in fact impede, not help, patients' decisions. Still, IRBs may feel disempowered to make changes.

Partly, the scientific issues involved may be intricate, and IRBs may thus struggle to include important, but multifaceted issues. Forms may not clearly define, for instance, standard of care, distinguishing it from additional procedures and tests. A study may only change a relatively small element of treatment, but the form may nonetheless explain the standard treatment fully. ("The research is only a couple of extra blood tests or scans. So, do you need 20 pages of the side effects of the standard medications?" [IRB3]) 


\section{Unclear Regulations and Standards: When Is Enough Enough?}

IRBs grapple with dilemmas concerning at what point to stop making small changes in forms-what standards to adopt, and when is "enough enough"? At what point do changes constitute "nitpicking"? Some IRBs try to develop and follow implicit or explicit criteriae.g., that they could stand by the consent form if audited. Yet questions emerge about such criteria: e.g., whether protocols should simply be "good enough," and if so, what that means.

Interviewees may feel that "obsessiveness" about consents should be reduced, but nonetheless defend the status quo overall. "The system is good. Unfortunately, we need to change the bureaucracy and the pendulum swinging of dotting $i$ 's and crossing $t$ s." (IRB31)

Other interviewees felt that their standards for consent forms, and hence the need for additional edits, were in fact rising ("I have become increasingly less inclined to feel, "this looks like a good consent.' I feel more: 'I don't like what it says in this or that phrase."' [IRB7]) As a researcher, he is acutely aware of the trade-offs involved-slowing science. But he believes that changes help the research. Still, he struggles to balance these competing goals, aiming to have IRBs make all changes simultaneously, rather than through repeated iterations.

I'd like to feel we were advocates for the research, if properly done. One doesn't want to say, "OK, you've made these changes. Now, here are 6-8 more."

Occasionally, "I'm sorry we missed it, but can you please change this phrase" is fine. But in big complicated studies, it could go back and forth several times. That makes me uncomfortable. (IRB7)

Yet where exactly an IRB should draw the line in making additional changes on a draft of a form may be unclear. Some IRBs accept a consent being "good enough," even if not perfect.

It comes to: yes, the description of the study's purpose makes the main or most relevant points, even if it's not a good objective account of the study. In a 15-page form, the IRB might let a little confusion sit, rather than insist that the researcher makes that completely clear. (IRB7)

Still, these determinations can be highly subjective-whether the standard should be "perfect" or "good enough," how to decide, and whether a particular form has met the standard, whatever it is. As a researcher, he is lenient, but his stance was far from universal. IRB chairs may say, "the perfect can be the enemy of the good," but then make many changes-not all essential.

Only a few interviewees readily acknowledged potential disadvantages of nitpicking too much - that PIs may then spend less time on science, and support the IRB less. These interviewees tried to avoid "nitpicking consent forms to death"- to check and curb the degree to which IRBs focus on relatively insignificant matters.

I try to focus on protecting human subjects-not on the more trivial stuff. I won't let us get out of compliance. But the consent document is a relatively small piece of the process. If you had a perfect document, but whip through it at the speed of light, and hand it to the subject to sign, it wouldn't do any good. If you take enough time with the subjects, it doesn't matter that much what the consent form says. So, I tend not to pick these forms to death. If they attest to the elements in the regs, are not written only for college graduates, and the major elements-the risks and procedures - are detailed enough, I let it go. (IRB32)

Still, his attitude results in part from the fact that he himself is also a PI: 
I myself have submitted research to the IRB, and gotten consents back where every few sentences, the IRB made some stylistic change that's not as good; or they didn't like something. Researchers then spend more time on making a nice consent form, and perhaps less time on something more important, like actually consenting the subject. (IRB32)

Yet though certain individuals on IRBs may not be comfortable with "nitpickiness," their view may not prevail on the committee as a whole.

Unclear regulations and standards foster variations both between and even within single IRBs. An IRB may suggest changes to a form it has previously approved, fostering researcher frustration and resentment. "Faculty say, 'This has been approved for seven years.' But the consent is very, very technical. I can barely understand it." (IRB29)

\section{Too Much Focus on Forms, Not the Process}

IRBs also struggle with inherent limitations of these documents, and frequently argue that "informed consent is a process, not a form," though nonetheless focusing intensely on the form alone.

Consenting is not a one-time form, and you're in the study forever. It's...how are you feeling? Do you want to stay in it, or not? Doctors think, "Oh, they signed the form; that means they're in." (IRB3)

Yet IRBs generally lack resources to ensure that consent is more of a process (i.e., monitoring the process itself). Many IRBs considered doing audits, but felt unable to do so:

Informed consent is not just a form-it's a whole process. But when we start doing audits, I can't even imagine. It seems overwhelming: how we would keep up with every study. (IRB29)

IRBs may realize these limitations to overseeing the process; but see few, if any, options.

\section{Possible Solutions}

Some IRBs discussed and attempted various strategies to ameliorate these problems, though varying how and to what degree. To enhance understandability, IRBs frequently had nonphysicians (IRB staff, so-called "community" members, or others) edit these documents. Yet these individuals vary widely in their background, training, and sense of their mandate. One IRB had a member's 16-year-old daughter review consents.

Our IRB has a surgeon who has a 16-year-old daughter. He uses her as a sounding board: "Does this make sense? Do you know what subjects are being asked to do?" He says that if she can't figure it out, no one's going to be able to. That's a nice metric. (IRB3)

This teenager raises questions about risks that the committee does not-e.g., why anyone would want to enter a study:

She doesn't understand things that the committee didn't anticipate: what are the real risks and real purposes of the study. What am I being asked to do? How long is it going to take? How does this differ from treatment for this condition? Why would anyone do this? A lot of PIs don't have answers. (IRB3)

This feedback can considerably enhance comprehension, but increase the length of the forms. Why the IRB does not have a staff or community member, rather than this adolescent, perform this function is also unclear. 
Several interviewees mentioned the possibility of shorter consent forms-e.g., one-page "summaries," with an added, longer form available. Yet, none had yet attempted such an approach—often because of legal concerns.

Though some critics have called for more standardized forms, interviewees highlighted potential problems - needs for flexibility and adaptation of templates, and questions of what and how much to standardize. Templates can result from institutions' and funders' legal concerns. Yet, problems can emerge since in any particular study, IRBs may require inclusion of inapplicable elements.

Once a template has been written, ambiguities may emerge concerning when these elements should be included or excluded—e.g., certain risks may be possible, but not likely.

Our IRB very often has included information about harm to self and others, and required information about a referral for help if you feel stress as a result of the research. But students have wanted to interview professors about these professors' careers. Does it really make sense to talk to them about suicidality? (IRB22)

Still, IRBs may keep such statements in every form, even if inapplicable, due not only to liability concerns but to anxieties and inertia-feeling such information might help some participants. Moreover, the cost to IRBs of including such additional phrases is low.

Some IRBs have instituted checklists for each reviewer in assessing consents, but these lists, too, can become cumbersome and bureaucratic, lengthening documents. ("Reviewer forms are 12 pages for every consent form—with 65 items to check off!" [IRB3])

"Better education" of PIs (IRB31) may also help, and cost less than monitoring consent, but not fully resolve the underlying tensions.

\section{Discussion}

This study, the first to explore how IRBs view and make decisions about consent forms, highlights how these documents pose a series of challenges and dilemmas that can prompt variations between these committees, and impede efforts to simplify and shorten these documents. Despite urgings to improve consents, little progress has been made-partly, these data suggest, because of complex underlying tensions involving multiple stakeholders and institutions. Pressures to make forms longer and more complicated arise due to funders' and institutions' liability concerns, increasing complexity of research, and lack of prior relationships between many researchers and subjects. IRBs may try to counter these pressures, but not always successfully.

The ANPRM may help, but the fate of its recommendations is unclear. Partly, improving IRB reviews of consent forms may reflect several goals that can themselves conflict.

IRBs may seek to enhance the quality of these documents and counter researchers' biases, but face ambiguities and tensions concerning what and how much to include, with what level of complexity, and how "perfect" these forms need to be. Critical dilemmas underlie these questions-whether these documents are legal contracts, and if so, to what degree; whom these documents ultimately protect; and how to improve them. Different stakeholders may view these documents differently: as primarily ethical (to enhance beneficence and autonomy) versus legal (to protect against claims of negligence) (Faden \& Beauchamp, 1986). IRBs face tensions with PIs, too, because the three goals-clarifying language, reducing length, and making fewer changes - can clash. IRBs may seek to make forms more thorough versus simplifying and shortening them, and not fully consider the costs to 
researchers. The ANPRM seeks standardized templates and one-page summaries, but questions arise about what details to include. Adding details to increase informativeness can lengthen a document and lead to further differences among IRBs. Investigators alone may bear these costs, and no mechanism exists to check IRBs in their decisions.

IRBs often emphasize that consent should be ongoing, but don't generally monitor or promote this "process," and may in fact undermine it by overemphasizing the form itself, increasing focus on it, rather than on the quality of the interpersonal communication and relationship between the researcher and subject. As a result, participants may feel that the form is designed to protect the institution legally more than inform subjects about the study. Moreover, the notion that consent is a process may also serve to legitimize long and complicated forms: i.e., since the form is only part of the process, detailed discussions will presumably occur between the researcher and subject. Hence, IRBs may see an imperfect form as less problematic than they should.

The inherently subjective nature of these quandaries leads to variations and frustrations among researchers, and often IRBs themselves. IRBs may be aware of, and wrestle with, these tensions, but be unsure how to resolve these conflicts, and need further guidance.

Study participants may view informed consent differently than do IRBs and researchers (Dixon-Woods, 2007; Harper, 2007); and scholars have argued that IRBs need to trust researchers more (Miller \& Boulton, 2007), and that IRBs and researchers should move from strictly "audit" and "deficit" models of informed consent (whereby factual information is given to subjects [Dixon-Woods, 2007]). Yet the present data highlight how the legal liability concerns of institutions and industry funders may impede acknowledgment and fuller incorporation of participant perspectives. Though subjects may seek primarily to trust researchers, and see these forms merely as symbolic of trustworthiness, IRBs appear to see these forms less as symbols of trust than as literal concrete manifestations and factual descriptions of scientific procedures, and don't appear to recognize or take into account participants' views of the meanings of these forms. Yet this discrepancy appears to reflect the larger, institutional contexts and systems in which IRBs and PIs operate. Institutions and industry funders have different priorities, needs, and liability concerns that, along with increased complexity of research, and lack of prior relationships between many researchers and subjects, can lengthen and complicate forms. IRBs may try to counter these pressures, but not always successfully.

These data highlight how complex institutional dynamics, contexts and pressures, and underlying conceptual tensions and subjectivities can affect decisions about consents. Institutions, in general, operate in complex social systems, and should be seen not as static, but as engaged in dynamic relationships (Emirbayer 1997).

\section{Best Practices}

These data have several important implications for improving practice and policy. Multipronged efforts are needed. Importantly, IRBs must work to shift their views and approaches toward informed consent forms-to recognize how these various tensions may affect decisions in suboptimal ways. In response to questions in the ANPRM, these data suggest several factors that increase consent form length. These forms constitute one of the few aspects of researcher interactions with subjects-a very downstream process-that IRBs feel they can control. Moreover, IRB perceptions that researchers and funders, not IRBs, are often responsible for long consent forms can perpetuate excessive length. The Office for Human Research Protections (OHRP) and others should address these systemic issues-e.g., by issuing specific language clarifying the degrees to which these documents are or are not de facto legal documents. IRBs and others should also become more aware of and address 
ambiguities concerning who is responsible: many IRBs see researchers' long and complicated forms as unalterable, feeling unable to change them, despite ostensible federal mandates to do so. Yet researchers may think that IRBs want such lengthy and detailed forms.

Though the ANPRM is considering "prescribing appropriate content" for these forms, questions about how information should be presented involve both form and content. While the ANPRM suggests, e.g., presenting information at the very beginning of the consent document, questions remain that will need to be tackled about the specific language to be used there (i.e., the exact amount and complexity of detail). The ANPRM also raises the possibility of one-page summaries, which can potentially be helpful; but ambiguities also need to be addressed with regard to what exactly these summaries should include, and whether lawyers representing industry funders and institutions will feel comfortable with, and permit, such abbreviation. ANPRM recommendations for change are valuable, and worth pursuing, but heightened recognition of the complexities involved is crucial.

While the ANPRM seeks templates, but avoidance of "boilerplates," the distinction between these two can blur in practice. Such forms may reduce variations among IRBs, but be applied too fully and rigidly by certain committees. IRBs may require inclusion of parts that do not apply in particular studies. Hence, any such efforts at standardization should include clear statements that these portions may apply only where indicated. Though such a statement may seem obvious and unnecessary, IRBs may nonetheless include such parts of templates when these are not needed.

OHRP and other policymakers should address and try to resolve the degrees to which consent forms are legal contracts. Uncertainty about this question furthers the efforts of funders and institutions to make these forms longer and more complicated, and can limit the effectiveness of efforts to shorten these documents.

In certain ways, these forms appear partly to be both legal and informational documents. Hence, IRBs should acknowledge and address this tension. In part, these forms may be seen as potentially protecting the institution. To think otherwise may be unrealistic. Thus, it may make sense to admit, rather than deny that fact, and to assess how best to bridge these potentially conflicting models and roles.

OHRP standards could also promulgate when exactly "enough is enough." IRBs should become more aware of these phenomena-e.g., that their intense focus on these forms can become counterproductive, making researchers feel that the form itself is what is important. Sensitivity can be increased on IRBs with regard to the costs of "nitpicking" too much, and checks and balances could be established. From a systems point of view, the lack of checks and balances creates problems. Such a feedback loop is critical. Presently, IRBs have little incentive to shorten and simplify forms. With regard to other proposed changes, the ANPRM suggests having IRBs report to OHRP how often they go beyond or deviate from certain length recommendations. Such reporting can potentially help motivate IRBs to follow these recommendations more fully. OHRP could potentially require that these forms be publicly available and posted on clinicaltrials.gov, to increase transparency and feedback.

Tests of comprehension have been suggested, but questions remain of what, how, and to what degree these should be administered to avoid rote memorization of answers (Flory \& Emanuel, 2004; Stiles, 2001). Moreover, questions arise of whether such tests should just be given once immediately upon entering a study, or repeated over time. If repeated, what should happen if subjects are found to remember and comprehend less over time is unclear. 
Some IRBs have established their own standards, "rules of thumb," or best practices that may be effective, and can potentially be disseminated elsewhere. Tensions about whom these forms in fact protect reflect larger questions that IRBs and policies should explore and address concerning who are the IRBs' primary clients-participants, institutions, funders, PIs, or the IRB itself-and how IRBs should determine and balance their responsibilities and roles with respect to each of these stakeholders. Ideally, it would seem that IRBs should be dedicated primarily to protecting subjects and should be aware that the notion of serving others (e.g., institutions) can generate COIs.

The ANPRM also proposes "excusing" certain studies from IRB review, yet these data suggest that IRBs may play potentially important roles in reviewing consent forms, and checking for potential biases in researchers' statements about protocols. If studies are excused, academic departments may then be responsible for reviewing studies internally, but be conflicted, wanting to advance faculty research, especially if the department receives indirect costs. The current system of having two parties involved-researchers pursuing science, and the IRBs checking for biases and protecting subjects-may yield certain advantages. How departments would approach and resolve any COIs they may then face is unclear, highlighting needs for research on these issues.

\section{Research Agenda}

These data suggest further needs for research as well—e.g., examining among larger samples how IRBs view, approach, and resolve these conflicts differently, and what institutional or sociodemographic factors are involved. Future studies can assess to what degrees IRB chairs and members see consent forms as legal contracts, when exactly they disagree as to when a form is "good enough vs. can be further refined," how much and in what specific ways they feel obligated to protect institutions and/or funders; and how study participants view these documents (i.e., as "informational vs. warrants of trust $v s$. legal contracts"). Both normative and empirical scholarship is needed, too, to probe questions of exactly how informed subjects should be; what and how much information to include, and how to decide; and to what degrees these forms are legal contracts.

\section{Educational Implications}

These data highlight needs for enhanced education and awareness of several areas among IRBs, researchers, policymakers, and others. More explicit awareness of these tensions can improve reviews of these documents. IRBs, OHRP, PRIM\&R (Public Responsibility in Medicine and Research), and other organizations could also potentially develop and disseminate materials to help train and guide IRBs in addressing these realms, establishing explicit standards concerning how to approach these tensions. OHRP could develop standard consent forms, addressing both the form and content; and IRB staff, members, and chairs can be required to undergo training using such standard consent forms, to reach consensus concerning acceptable and appropriate consent and lengths. The limitations of consents, and the ongoing need for flexibility, are also critical to instill.

This study has several potential limitations. I interviewed IRB chairs and members, but not PIs or study participants, and did not directly observe IRBs as a whole, or examine written IRB records; but future studies can do so. However, directly observing IRBs may be difficult since, anecdotally, IRBs have generally required that researchers obtain consent from all IRB members, PIs, and funders whose studies are being reviewed at such meetings. These data are qualitative, and thus are designed to reveal-in many ways that quantitative data cannot—attitudes, beliefs, and experiences, generating research questions and hypotheses that future investigations can probe in further detail among larger samples. 
Qualitative research is not designed to measure responses quantitatively, but future investigations can do so.

In sum, these data suggest several challenges and tensions, but also directions for improving informed consent for human subject research.

\section{Supplementary Material}

Refer to Web version on PubMed Central for supplementary material.

\section{Acknowledgments}

The author would like to thank Meghan Sweeney, Jason Keehn, Renée Fox, Paul Appelbaum, and Patricia Con-tino for their assistance with this manuscript. This work was supported by the National Institutes of Health [R01NG04214] and the National Library of Medicine [5-G13-LM009996-02].

\section{References}

Albala I, Doyle M, Appelbaum PS. The evolution of consent forms for research: A quarter century of changes. IRB: Ethics \& Human Research. 2010; 32(3):7-11. [PubMed: 20590051]

Bell, J.; Whiton, J.; Connelly, S. Final report: Evaluation of NIH implementation of section 491 of the Public Health Service Act, mandating a program of protection for research subjects. Arlington, VA: James Bell Associates; 1998.

Campbell EG, Weissman JS, Clarridge B, Yucel R, Causino N, Blumenthal D. Characteristics of medical school faculty members serving on institutional review boards: Results of a national survey. Academic Medicine. 2003; 78(8):831-836. [PubMed: 12915379]

Cohn E, Larson E. Improving participant comprehension in the informed consent process. Health Policy and Systems. 2007; 39(3):273-280.

Dawson L, Kass NE. Views of U.S. researchers about informed consent in international collaborative research. Social Science and Medicine. 2005; 61(6):1211-1222. [PubMed: 15970232]

de Vries RG, Forsberg CP. Who decides? A look at ethics committee membership. Healthcare Ethics Committee Forum. 2002; 14(3):252-258.

Dixon-Woods M. Interpreting change: The role of qualitative research in evaluating interventions in chronic respiratory disease. Chronic Respiratory Disease. 2007; 4(3):127-128. [PubMed: 17711909]

Dixon-Woods M, Ashcroft RE, Jackson CJ, Tobin MD, Kivits J, Burton PR, Samani NJ. Beyond "misunderstanding": Written information and decisions about taking part in a genetic epidemiology study. Social Science and Medicine. 2007; 65(11):2212-2222. [PubMed: 17904716]

Dziak K, Anderson R, Sevick MA, Weisman CS, Levine DW, Scholle SH. Variations among institutional review boards in a multisite health services research study. Health Services Research 2005; 40(1):279-290. [PubMed: 15663713]

Emirbayer M. Manifesto for a relational sociology. American Journal of Sociology. 1997; 103(2):281317.

Faden, RR.; Beauchamp, TL. A history and theory of informed consent. New York: Oxford University Press; 1986.

Flory J, Emanuel E. Interventions to improve research participants' understanding in informed consent for research. Journal of the American Medical Association. 2004; 292(13):1593-1601. [PubMed: 15467062]

Geertz, C. Interpretation of cultures: Selected essays. New York: Basic Books; 1973.

Greene SM, Geiger AM. A review finds that multicenter studies face substantial challenges but strategies exist to achieve institutional review board approval. Journal of Clinical Epidemiology. 2006; 59(8):784-790. [PubMed: 16828670]

Harper I. Translating ethics: Researching public health and medical practices in Nepal. Social Science and Medicine. 2007; 65(11):2235-2247. [PubMed: 17897762] 
Klitzman R. Views and experiences of IRBs concerning research integrity. Journal of Law, Medicine and Ethics. 2011a; 39(3):513-528.

Klitzman R. "Members of the same club": Challenges and decisions faced by U.S. IRBs in identifying and managing conflicts of interest. PLoS ONE. 2011b; 6(7):e22796. [PubMed: 21829516]

Klitzman R. The ethics police?: IRBs' views concerning their power. PLoS ONE. 2011c; 6(12):e28773. [PubMed: 22174893]

Klitzman R. How local IRBs view central IRBs in the U.S. BMC Medical Ethics. 2011d; 12(13) Available at http://www.biomedcentral.com/1472-6939/12/13.

Klitzman R. The myth of community differences as the cause of variations among IRBs. American Journal of Bioethics, Primary Research. 2011e; 2(2):24-33.

Klitzman R. Institutional Review Board community members: Who are they, what do they do, and whom do they represent? Academic Medicine. 2012a; 87(7):975-981. [PubMed: 22622206]

Klitzman R. U.S. IRBs confronting research in the developing world. Developing World Bioethics. 2012b; 12(2):63-73. [PubMed: 22515423]

Krosin M, Klitzman R, Levin B, Cheng J, Ranney ML. Problems in comprehension of informed consent in rural and peri-urban Mali, West Africa. Clinical Trials. 2006; 3(3):306-313. [PubMed: 16895047]

Miller T, Boulton M. Changing constructions of informed consent: Qualitative research and complex social worlds. Social Science and Medicine. 2007; 65(11):2199-2211. [PubMed: 17904717]

Molyneux CS, Peshu N, Marsh K. Trust and informed consent: Insights from community members on the Kenyan coast. Social Science and Medicine. 2005; 61(7):1463-1473. [PubMed: 16005781]

O'Neill O. Accountability, trust and informed consent in medical practice and research. Clinical Medicine. 2004; 4(3):269-276. [PubMed: 15244364]

Paasche-Orlow MK, Taylor HA, Brancati FL. Readability standards for informed-consent forms as compared with actual readability. New England Journal of Medicine. 2003; 348:721-726. [PubMed: 12594317]

Shah S, Whittle A, Gensler G, Wendler D. How do institutional review boards apply the federal risk and benefit standards for pediatric research? Journal of the American Medical Association. 2004; 291(4):476-482. [PubMed: 14747505]

Stark AR, Tyson JE, Hibberd PL. Variation among institutional review boards in evaluating the design of a multicenter randomized trial. Journal of Perinatology. 2009; 30(3):163-169. [PubMed: 19798046]

Stark, L. Behind closed doors: IRBs and the making of ethical research (Morality and Society Series). Chicago: The University of Chicago Press; 2012.

Stiles PG. Improving understanding of research consent disclosures among persons with mental illness. Psychiatric Services. 2001; 52:780-785. [PubMed: 11376225]

Strauss, A.; Corbin, J. Basics of qualitative research: Techniques and procedures for developing grounded theory. Newbury Park, CA: Sage; 1990.

U.S. Department of Health and Human Services. Human subjects research protections: Enhancing protections for research subjects and reducing burden, delay, and ambiguity for investigators. Federal Register (July 26). 2011; 76:44512-44531.

\section{Biography}

Robert Klitzman is Professor of Clinical Psychiatry and Director of the Masters of Bioethics Program at Columbia University. 
TABLE 1

Characteristics of the Sample of IRB Chairs, Members, and Administrators.

\begin{tabular}{|c|c|c|}
\hline & Total & $\%(\mathrm{~N}=46)$ \\
\hline \multicolumn{3}{|l|}{ Type of IRB Staff } \\
\hline Chairs/Co-Chairs & 28 & $60.87 \%$ \\
\hline Directors & 1 & $2.17 \%$ \\
\hline Administrators & 10 & $21.74 \%$ \\
\hline Members & 7 & $15.22 \%$ \\
\hline \multicolumn{3}{|l|}{ Gender } \\
\hline Male & 27 & $58.70 \%$ \\
\hline Female & 19 & $41.30 \%$ \\
\hline \multicolumn{3}{|l|}{ Institution Rank } \\
\hline $1-50$ & 13 & $28.26 \%$ \\
\hline $51-100$ & 13 & $28.26 \%$ \\
\hline $101-150$ & 7 & $15.22 \%$ \\
\hline $151-200$ & 1 & $2.17 \%$ \\
\hline $201-250$ & 12 & $26.09 \%$ \\
\hline \multicolumn{3}{|l|}{ State vs. Private } \\
\hline State & 19 & $41.30 \%$ \\
\hline Private & 27 & $58.70 \%$ \\
\hline \multicolumn{3}{|l|}{ Region } \\
\hline Northeast & 21 & $45.65 \%$ \\
\hline Midwest & 6 & $13.04 \%$ \\
\hline West & 13 & $28.26 \%$ \\
\hline South & 6 & $13.04 \%$ \\
\hline Total \# of Institutions Represented & & 34 \\
\hline
\end{tabular}


TABLE 2

Themes Concerning IRB Approaches Toward Consent Forms.

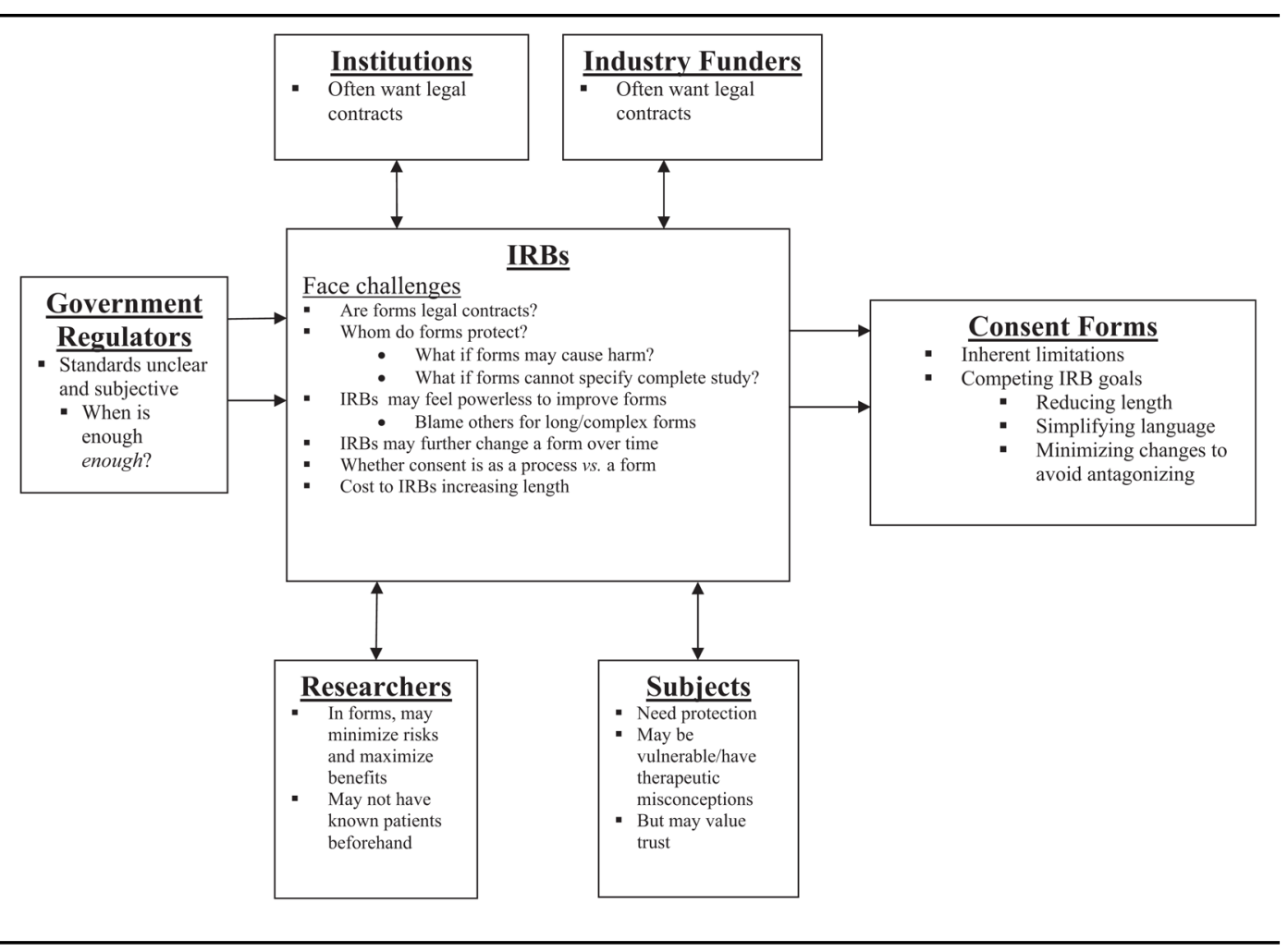

